\title{
ARTICLE OPEN Steady states and transport processes in urban ozone balances
}

\author{
M. A. K. Khalil ${ }^{1}$
}

Core chemical theory is combined with transport processes and local emissions to study the validity of commonly made assumptions regarding steady states to interpret urban and regional ozone data. It is shown that photo-stationary states of NO and $\mathrm{NO}_{2}$ cannot exist in urban areas or polluted regions in addition to the lack of such a state for ozone. Calculations in published papers, which make the assumption of a photo-stationary state for $\mathrm{NO}$ and $\mathrm{NO}_{2}$, or ozone, are likely to be inaccurate by unacceptable amounts. The Leighton Ratio is re-interpreted to show how it incorporates both the peroxy radical and transport effects on ozone, separating local chemical production from its transport. To illustrate the concepts and test the assumptions, hourly observations of ozone and its precursors from Yanbu in Saudi Arabia are analyzed. The major role of local transport processes and a large import of ozone at night, probably from aloft, are uncovered as a by-product.

npj Climate and Atmospheric Science (2018)1:22; doi:10.1038/s41612-018-0035-7

\section{INTRODUCTION}

Ozone is one the most common pollutants in the urban areas of the world. Because of its adverse environmental and health effects, laws and regulations have been implemented world-wide to control its precursors, which are oxides of nitrogen and hydrocarbon gases emitted from automobiles, industrial processes, and natural sources. The production and destruction of ozone in urban atmospheres follows well known chemical and physical laws but how these are manifested in a particular environment can lead to major differences in the level of pollution that actually occurs. ${ }^{1-3}$

The goal of this paper is to establish a theoretical framework for the mass balance of ozone at urban and regional sites that takes into account the combined effects of core chemistry, transport processes, and local emissions. This leads to a novel approach to assess ozone balances and is especially applicable to a common situation in which spatial concentration measurements, emissions inventories, and meteorological data are not available for more detailed numerical chemistry-transport modeling. It is being presented here partly because in past publications assumptions have been made about photo-stationary states in the urban ozone core chemistry that are invalid and lead to faulty results. In this context the frequently calculated Leighton ratio is re-interpreted to further inform the analysis of urban ozone data sets.

The general mechanism of ozone formation in urban areas is determined by emissions of nitrogen oxides $\left(\mathrm{NO}, \mathrm{NO}_{2}\right)$ and reactive organic carbon compounds (VOCs). Ozone, and possibly most of the $\mathrm{NO}_{2}$, are formed and destroyed by atmospheric chemical processes that can be described by the following core set of reactions. ${ }^{4-7}$

$$
\begin{aligned}
& \mathrm{R} 1: \mathrm{VOC}_{\mathrm{i}}+\mathrm{OH} \rightarrow \mathrm{R}^{\mathrm{O}_{2}}+\text { other molecules } \\
& \mathrm{R} 2: \mathrm{R}_{2}+\mathrm{NO} \rightarrow \mathrm{NO}_{2}+\text { other molecules } \\
& \mathrm{R} 3: \mathrm{NO}_{2}+\mathrm{O}_{2}+\mathrm{h} \nu \rightarrow \mathrm{NO}+\mathrm{O}_{3} \\
& \mathrm{R} 4: \mathrm{O}_{3}+\mathrm{NO} \rightarrow \mathrm{NO}_{2}+\mathrm{O}_{2}
\end{aligned}
$$

In this system, NO, VOCs, and some $\mathrm{NO}_{2}$ are emitted by combustion processes, often from transportation or industrial activities. Sunlight initiates the production of $\mathrm{OH}$ that oxidizes the VOCs to generate the intermediate peroxy radicals $\mathrm{R}^{\prime} \mathrm{O}_{2}\left(\mathrm{HO}_{2}\right.$ or $\mathrm{RO}_{2}$ in R1). These radicals react with $\mathrm{NO}$ converting it to $\mathrm{NO}_{2}(\mathrm{R} 2)$. The subsequent breakdown of $\mathrm{NO}_{2}$ by sunlight makes $\mathrm{O}_{3}$ in two steps (R3) $\left(\mathrm{NO}_{2}+\mathrm{hv} \rightarrow \mathrm{NO}+\mathrm{O}\right.$ and then $\left.\mathrm{O}+\mathrm{O}_{2}+\mathrm{M} \rightarrow \mathrm{O}_{3}+\mathrm{M}\right)$. In this process, the VOCs stimulate the production of ozone because they reduce NO, which is a rapid sink of ozone (R4) and increase $\mathrm{NO}_{2}$ (R2) that allows more ozone to be made. The ozone and nitrogen oxides cycle through these chain reactions creating high levels of ozone that affect human health and life. Aside from this core set of processes there are other, much slower reactions, that lead to the termination of these catalytic cycles.

The process of developing the results used data on ozone and its precursors to test and explore the assumptions and outcomes of urban ozone balances. These data were acquired from Saudi Arabia's Presidency of Meteorology and Environment (PME) and WeatherSpark as described in our earlier research. ${ }^{8,9}$ The $J_{\mathrm{NO} 2}$ for reaction R3 was calculated using the TUV model including the effects of clouds and urban albedos for each hour of the year thus taking into account the diurnal and seasonal effects. ${ }^{10}$ The resulting information available to us is summarized in Fig. 1 as a regular diurnal cycle which is the most prominent characteristic of urban ozone and is the focus of environmental regulations.

\section{RESULTS}

The three results of this study are: (1) It is proved that because the transport and chemical processes (R1-R4) are intimately tied together, there can be no photo-stationary state of ozone or its precursors $\mathrm{NO}$ and $\mathrm{NO}_{2}$ (see the Methods section). (2) For ozone observations, especially in urban areas, local transport process are major contributors to its balance. Ozone is transported because it's lifetime is sufficiently long, while the $\mathrm{NO}$ and $\mathrm{NO}_{2}$ transport because they regenerate each other making NOx a chemically conserved quantity on the time scales of urban photochemistry.

${ }^{1}$ Department of Physics, Portland State University, P.O. Box 751, Portland, OR 97207, USA

Correspondence: M A. K. Khalil (aslamk@pdx.edu)

Received: 4 December 2017 Revised: 1 March 2018 Accepted: 17 May 2018

Published online: 02 July 2018 


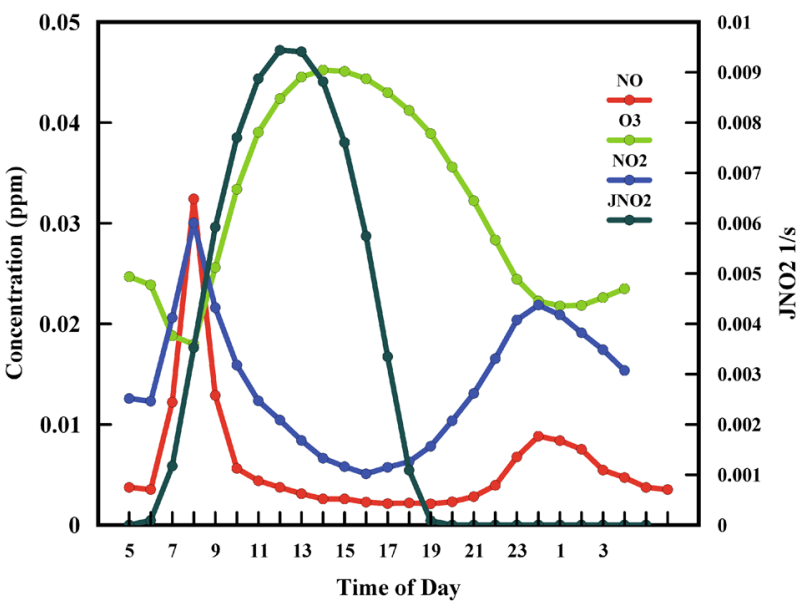

Fig. 1 The chemical components of the mass balance of ozone at Yanbu. Measured hourly concentrations of ozone and precursors $\left(\mathrm{NO}, \mathrm{NO}_{2}\right.$ ) over six years and model calculations of $J_{\mathrm{NO} 2}$ for each hour of the day during a year

(3) The frequently calculated Leighton ratio of chemical production to destruction of ozone can be used to separate the effects of transport from chemistry. Although it can exceed unity entirely due to the action of the VOC's on the partitioning of $\mathrm{NO}$ and $\mathrm{NO}_{2}$, it is often observed to be well below one, which is explained only by the transport component inherent in the ratio.

These results are illustrated by application to data from Yanbu. The mass balances are shown in Figs. 2-4, where the major effect of local transport is evident for ozone and NOx. The Leighton ratio in Fig. 5 shows both that it is less than one for a significant part of the day, and its implication of how the ozone concentration is affected by transport either out from the site, or into the site.

\section{DISCUSSION}

Let us examine the salient points demonstrated by the ozone balance at Yanbu. It is evident that transport is a major component of the mass balance at all times of the day and that there is a substantial net transport of ozone into the site late during the day and continuing into the night until morning. In Fig. 1 we see evidence that there are significant nighttime emissions of $\mathrm{NO}$ and $\mathrm{NO}_{2}$ that appear as secondary maxima in the hourly data. This is expected from the nightlife which is prevalent in the hot desert cities. ${ }^{11}$ Because of this, the lifetime of ozone is still only 10-20 min at night (Fig. 3). Since there is no nighttime production of ozone by any known mechanisms, and there is plenty of ozone present, it has to be transported from aloft or the surrounding areas.

There are several observations that show high levels of ozone outside or above the cities of Saudi Arabia as reported for Jeddah and Alsodah. ${ }^{12-14}$ The idea proposed here is that ozone and more so its precursors, VOCs, and $\mathrm{NO}_{2}$ are exported from the cities, resulting in the high ozone in surrounding areas and aloft because NO concentrations are lower there. This generates and preserves the ozone aloft which is brought back at night. ${ }^{15} \mathrm{~A}$ possible picture is that $\mathrm{NO}$, emitted from night traffic, wafts into the observation site, mixing with ozone that is transported downwards in the same air mass from higher levels aloft. Both NO and ozone are destroyed in their mutual reaction and what leaves the site is less ozone and $\mathrm{NO}$ than came in, and more $\mathrm{NO}_{2}$ formed in the reaction. This phenomenon is not specific to Yanbu because similar results are found in other Saudi cities. ${ }^{10}$

The $\mathrm{NO}$ and $\mathrm{NO}_{2}$ transport is a major components of their budgets, although this can only be calculated for the nighttime conditions, but it can be inferred that the similarly large and persistent transport would be required during the day. The existence of the sizable transport components obviate any photostationary states for $\mathrm{NO}, \mathrm{NO}_{2}$, or $\mathrm{O}_{3}$, but admit pseudo-steady states. NOx transport to the observation site at Yanbu was calculated so that $\mathrm{d}(\mathrm{NOx}) / \mathrm{d} t=$ TnetNOx (Eqs. 2, 3, 7 in "Methods"). The results demonstrate that the $\mathrm{NO}$ and $\mathrm{NO}_{2}$ are continually transported to the site and the patterns are consistent with known emissions during the morning and late evening when we see net fluxes into the region of the observation site (Fig. 4). It supports the point that $\mathrm{NO}$ and $\mathrm{NO}_{2}$ cannot be in a photo-stationary state during the day because of the substantial transport that is occurring. Due to lack of data on VOCs or the peroxy radicals, we cannot estimate the transport of $\mathrm{NO}$ and $\mathrm{NO}_{2}$ separately. Moreover, the net transport of NOx is much smaller than the inflows and outflows, which we also cannot estimate separately. At night however, since there are no peroxy radicals and NO is not regenerated because there is no photolysis of $\mathrm{NO}_{2}$, we see that the observed concentrations of ozone, $\mathrm{NO}$, and $\mathrm{NO}_{2}$ require a large net import of NO at about $140 \mathrm{ppb} / \mathrm{h}(18: 00-04: 00 \mathrm{~h})$ and a net export of $\mathrm{NO}_{2}$ at about the same rate leaving a small residual accumulation of NOx shown in Fig. 4 (Based on Eq. 7 in "Methods"). The required nighttime ozone influx is $\sim 130 \mathrm{ppb} / \mathrm{h}$ (Fig. 3).

It is noteworthy that the calculated transport of ozone or the precursors does not represent the exchange between Yanbu and the outside environment, but is driven by local gradients, especially during the day when such gradients of ozone and its precursors can be large due to the inhomogeneous nature of the emissions in urban areas and subsequent chemistry. Since our measurements are only at one site, this aspect cannot be evaluated quantitatively. Locations in the city where ozone concentrations are highest would show net outward transport for more of the day and sites where the concentrations are low may have net inward transport throughout the day. One aspect of estimating the transport effect is that if a site is mostly importing ozone, it is not the place where the highest concentrations will exist, and therefore it may be inadequate to determine compliance with standards. At night the local gradients may be lessened because there is no production but the sink can still be widely different from place to place inside the city.

There is a remarkable year to year consistency in the patterns of ozone generation and transport. The atmosphere around the site is a net sink of ozone when taken over the whole day even though high net production rates occur between 08:00 and 14:00 h averaging about $80 \mathrm{ppb} / \mathrm{hr}$. For the six years on average the daytime (07:00-18:00) net production is about $7 \mathrm{ppb} / \mathrm{hr}$ and the nighttime (19:00-06:00) net loss is $130 \mathrm{ppb} / \mathrm{hr}$ resulting in a net loss of ozone over the $24 \mathrm{~h}$ of $\sim 60 \mathrm{ppb} / \mathrm{h}$. The ozone destroyed at night is presumed to be generated from the precursors that leave the city core and are brought back at night, thus making other parts of the city or the air aloft, net producers of ozone.

\section{METHODS}

The mass balance of ozone at Yanbu

From R1-R4, we can write the net chemical production rates for the core processes, $\mathrm{P}_{\mathrm{Net}} \mathrm{C}$ as:

$$
\begin{aligned}
& \mathrm{P}_{\mathrm{Net}} \mathrm{O}_{3}=J_{\mathrm{NO} 2}\left(\mathrm{NO}_{2}\right)-k_{4}\left(\mathrm{O}_{3}\right)(\mathrm{NO}), \\
& \mathrm{P}_{\mathrm{Net}} \mathrm{NO}=J_{\mathrm{NO} 2}\left(\mathrm{NO}_{2}\right)-k_{2}\left(\mathrm{R} / \mathrm{O}_{2}\right)(\mathrm{NO})-k_{4}\left(\mathrm{O}_{3}\right)(\mathrm{NO}), \\
& \mathrm{P}_{\mathrm{Net}} \mathrm{NO}_{2}=k_{2}\left(\mathrm{R} / \mathrm{O}_{2}\right)(\mathrm{NO})+k_{4}\left(\mathrm{O}_{3}\right)(\mathrm{NO})-J_{\mathrm{NO}_{2}}\left(\mathrm{NO}_{2}\right), \\
& \mathrm{P}_{\mathrm{Net}} \mathrm{R}^{\mathrm{O}} \mathrm{O}_{2}=\sum_{\mathrm{i}} k_{\mathrm{i}}(\mathrm{VOCi})(\mathrm{OH})-k_{2}\left(\mathrm{R}_{2}\right)(\mathrm{NO}),
\end{aligned}
$$

where $k_{2}\left(\mathrm{R}^{\prime} \mathrm{O}_{2}\right) \equiv\left[k_{2 \mathrm{a}}\left(\mathrm{RO}_{2}\right)+k_{2 \mathrm{~b}}\left(\mathrm{HO}_{2}\right)\right]$. The general mass balance for the concentration of each of these chemicals at the point of observation can 

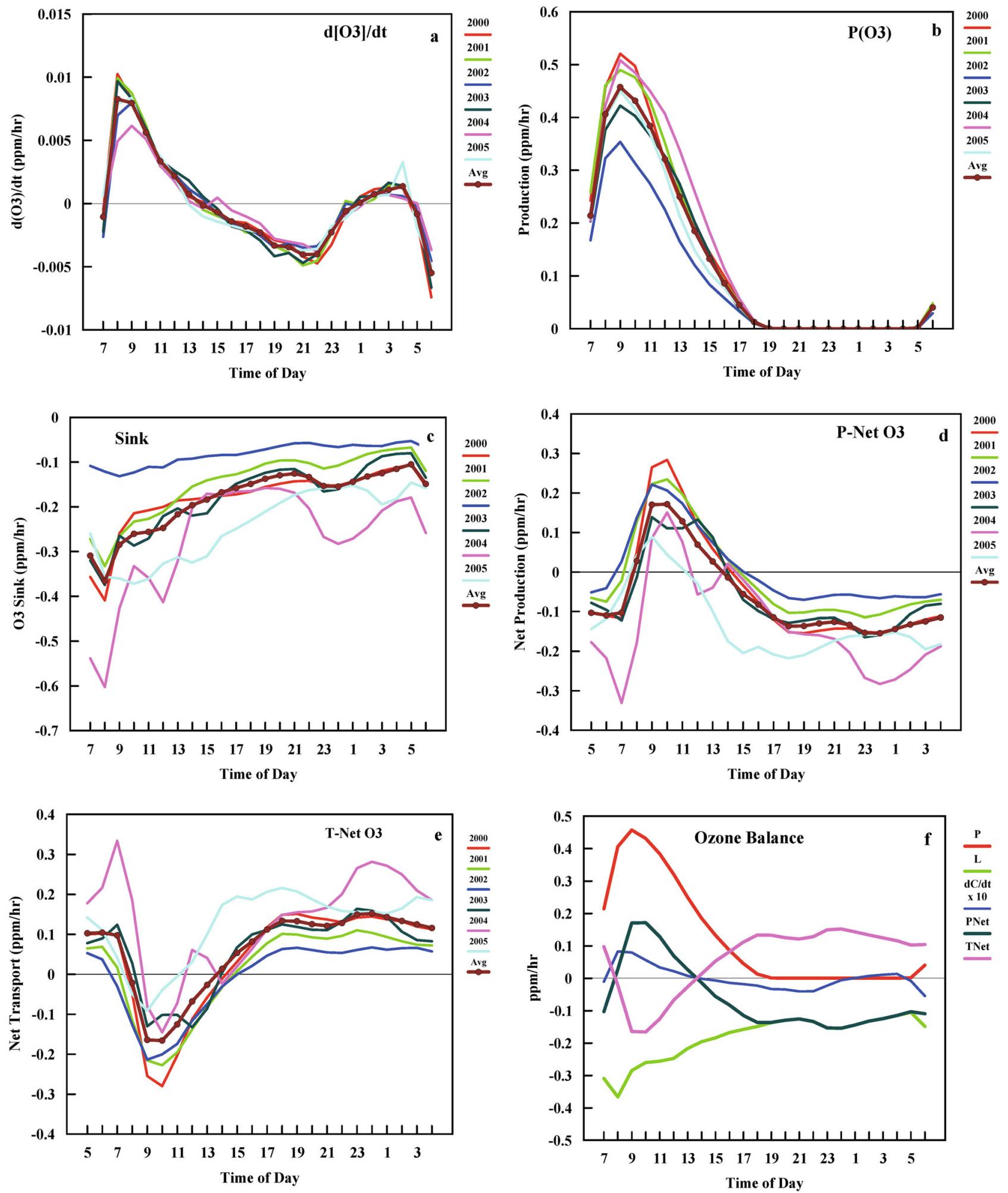

Fig. 2 The mass balance of ozone at Yanbu: a rate of change, $\mathbf{b}$ production, $\mathbf{c}$ loss, $\mathbf{d}$ net production, e net transport, and $\mathbf{f}$ composite of all years. A positive net transport means that ozone is being imported into the site from surrounding areas including the air above. Net transport is negative when the site is exporting ozone during peak emissions of the precursors in early morning

be written as:

$\partial C / \partial t=P_{\mathrm{Net}} C+\left(S-C / \tau_{\text {Other }}\right)-T_{\mathrm{Net}} C$

$T_{\mathrm{Net}} C=\nabla \cdot(v C)-\nabla \cdot(K . \nabla C)$ in Eq. (5), $C$ is the concentration of the gases mentioned in the set of reactions, $P_{\mathrm{Net}} C$ is the net chemical production as described in Eqs. (1-4) in our case, $S$ are the direct emissions at the point represented by the equation and $\tau_{\text {Other }}$ are potential non-chemical sinks such as deposition for ozone or additional chemical sinks not included in the core chemistry of $\mathrm{R} 1-\mathrm{R} 4$, such as reactions that lead to a termination of the main 


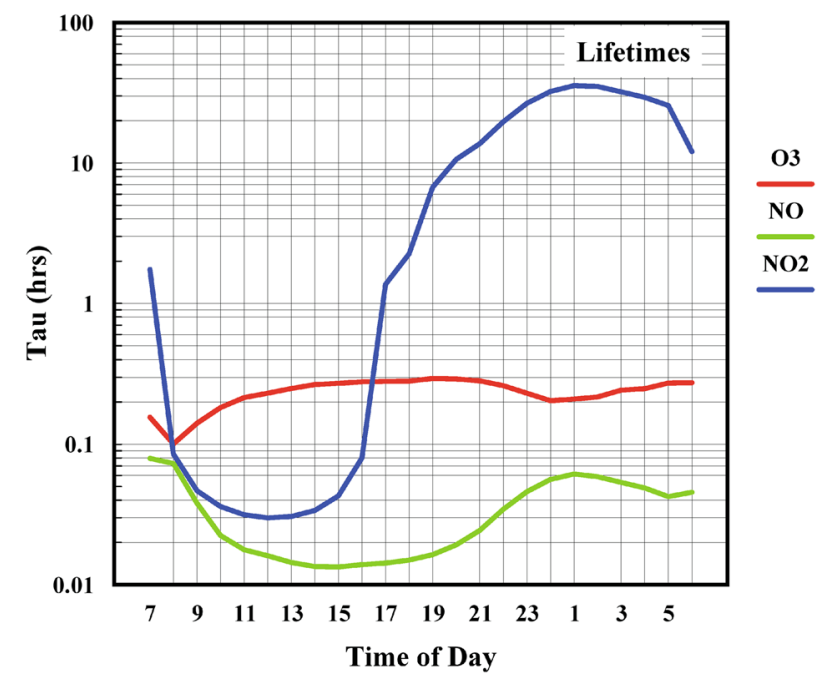

Fig. 3 The local lifetimes of $\mathrm{NO}, \mathrm{NO}_{2}$, and $\mathrm{O}_{3}$ at Yanbu. For ozone several known sinks are not included because the estimated effect of all of them combined is less than $10 \%$ of the local NO sink for this site. The daytime lifetime of NO is an upper limit since reactions with peroxy radicals are not included because of lack of data. For $\mathrm{NO}_{2}$ the nighttime sink is based on the reaction with ozone, which is negligible during the day due to the strong photolysis

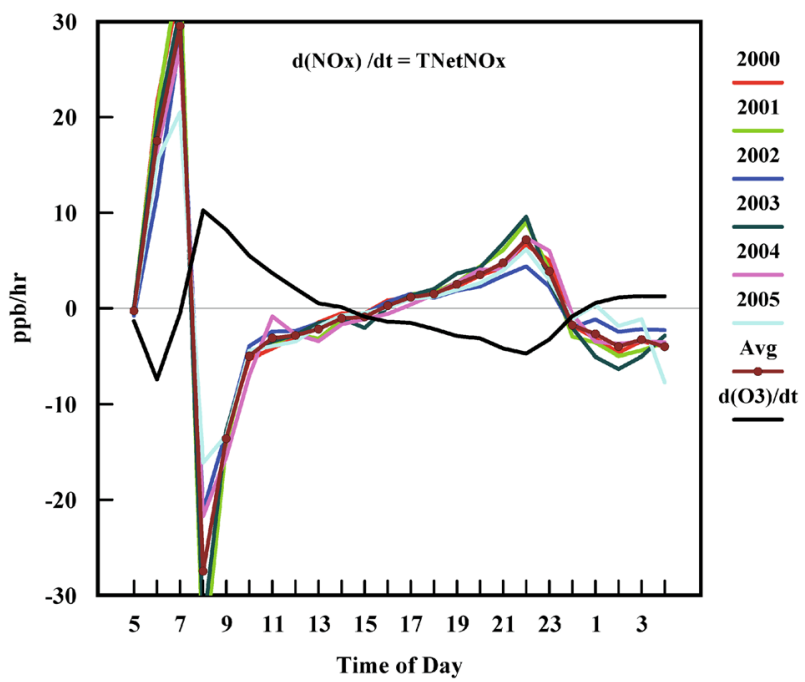

Fig. 4 The calculated rate of net transport of $\mathrm{NOx}$ as $T_{\mathrm{Net}} \mathrm{NOx}=\mathrm{d}$ (NOx)/dt. For comparison, the rate of change of ozone concentration is included showing an inverse relationship. The net flux of NOx is much smaller than the actual influxes and outfluxes of $\mathrm{NO}$ and $\mathrm{NO}_{2}$ but it shows a continual transport flow making $P_{\mathrm{Net}} \mathrm{NO}$ and $P_{\mathrm{Net}} \mathrm{NO}_{2}$ $\neq 0$

NO- $\mathrm{NO}_{2}-\mathrm{O}_{3}$ cycles. The transport terms are driven by the winds $\mathbf{v}$ and turbulence efficiencies $\mathbf{K}$. The effect of transport however, also clearly depends on the concentration gradients that exist near the site at which this balance is evaluated. Measurements taken at one location therefore are not sufficient to evaluate the $T_{\mathrm{Net}} \mathrm{C}$ term directly.

A simpler equation is obtained by integrating Eq. (5) over some small volume $\delta \mathrm{V}$ surrounding the site within which the concentrations are represented by the measurements. The net transport is: $T_{\mathrm{Net}} C=T_{\mathbb{I N}} C-$ $T_{\text {OUT }} C$ where the inflow $T_{\text {IN }} C$ is dependent on the concentrations outside the area represented by the measurements. Transport efficiencies can be described by an effective transport time $\tau_{\mathrm{T}}$ so that: $T_{\mathrm{OUT}} C=\left(1 / \tau_{\mathrm{T}}\right) C$ and Eq.
(5) can be written in the following form ${ }^{16}$ :

$\mathrm{dC} / \mathrm{dt}=\left(P+T_{\mathrm{IN}} C\right)-\left(1 / \tau+1 / \tau_{\mathrm{T}}\right) C$

$P_{\mathrm{Net}} \mathrm{C}=P-C / \tau$ where $\tau$ is the chemical lifetime. In Eq. (6) $T_{\mathrm{IN}}$ and $T_{\text {OUT }}$ are separated to emphasize that transport can act as a source or a sink that is indistinguishable from the chemical production and destruction in the mass balance. The direct source $S$ can be taken to be zero $(=0)$ if the averaging is over a small enough region that does not contain sources such as highways or factories, otherwise it can be added to the $\left(P+T_{\mathrm{IN}}\right)$ term. In that case however, since $C$ in the equation is the average concentration inside the volume $\delta V$, it may not accurately represent the concentration measured at the site. It is noteworthy that both Eqs. (5) and (6) represent local mass balances at a point or a small volume of the atmosphere and as such do not describe the city-wide balances without measurements at many sites or by making untenable assumptions.

The $P_{\mathrm{Net}}$ 's and $T_{\mathrm{Net}}$ 's are so named here because they reflect the explicit involvement of chemical reactions embodied in the rate constants $(k$ 's and $j$ 's) and the movement of the gases by the winds and turbulence ( $v^{\prime} s$ and $K^{\prime}$ s). However the calculation of the $P_{\mathrm{Net}}$ and $T_{\mathrm{Net}}$ for one gas includes the concentrations of other gases in the set which are inseparably affected by both transport and chemistry. This creates an implicit dependence of the $T_{\mathrm{Net}}$ 's on chemistry and of the $P_{\mathrm{Net}}$ 's on transport. We will consider only the explicit contributions in this study because the implicit contributions are already included in the measured concentrations of the gases at any chosen site as for the Yanbu circumstances.

We can now combine the core chemical processes and transport to write the mass balance Eq. (6) as:

$\mathrm{d} C / \mathrm{d} t=P_{\mathrm{Net}} C+T_{\mathrm{Net}} C$

$\mathrm{C}=\left(\mathrm{O}_{3}\right),(\mathrm{NO}),\left(\mathrm{NO}_{2}\right)$ or $\left(\mathrm{R} / \mathrm{O}_{2}\right)$

$P_{\mathrm{Net}} \mathrm{NO}_{2}=-P_{\mathrm{Net}} \mathrm{NO}$

$T_{\mathrm{Net}} \mathrm{R} / \mathrm{O}_{2}=0 \Rightarrow P_{\mathrm{Net}} \mathrm{R} / \mathrm{O}_{2}=0$

We have made some assumptions in writing Eqs. (7-9): peroxy radicals are assumed to be in a photo-stationary state with negligible transport, and slower cycle terminating reactions, including deposition, are neglected for the local balances represented by these equations. If additional chemical reactions have to be added to the core (R1-R4) then the $P_{\mathrm{Net}}$ 's in Eqs. (1-4) would have to be modified appropriately and would be reflected here. It is further assumed that there are no direct emissions within the region $\delta V$ represented by the measured concentrations.

Sources of ozone other than R3 are small if they exist at all., ${ }^{17,18}$ There are however, known sinks of ozone other than the reaction with NO (R4). These include $\mathrm{OH}, \mathrm{VOCs}$, solar UV, $\mathrm{NO}_{2}$, and dry deposition. We found that because of the high $\mathrm{NO}$ concentrations in the urban environments of our interest and specifically for point calculations at our observation sites, these other sinks together are less than $10 \%$ of the NO reaction (R4) at all times of the day and may be excluded from the local core equations. ${ }^{10}$ However, these processes terminate the chain reactions and are needed to balance ozone over city-wide or larger space and time scales.

The net production of ozone R3 and R4, does not have any additional molecules involved other than $\mathrm{NO}$ and $\mathrm{NO}_{2}$. The effects of individual VOCs, peroxy radicals generated from them and their various complex interactions therefore do not affect the calculation of net ozone production as long as measured concentrations of $\mathrm{NO}$ and $\mathrm{NO}_{2}$ are used in Eq. (1). We can say that the effects of the VOCs on ozone at any location are in the conversion of $\mathrm{NO}$ to $\mathrm{NO}_{2}$ and are already embodied in the measured concentrations of these gases.

Since we do not have measurements of the peroxy radicals, the daytime balance of $\mathrm{NO}, \mathrm{NO}_{2}$, and $\mathrm{R}^{\prime} \mathrm{O}_{2}$ cannot be determined from the Yanbu data (Eq. 2-4, 7). The mass balance of ozone however, can be constructed according to this framework. The direct measurements of $\mathrm{NO}_{1} \mathrm{NO}_{2}$, and $\mathrm{O}_{3}$ with an hourly integration, give us the ozone rate of change $\left(d\left(\mathrm{O}_{3}\right) / d t\right)$, production, loss, and net production $\left(P_{\mathrm{Net}} \mathrm{O}_{3}\right)$. Since we have data at only one site, there is no measure of the gradients and so the transport cannot be calculated directly. We evaluate it as the residual ozone needed to balance the net local production and the $d\left(O_{3}\right) / d t$ term. The rate $d\left(O_{3}\right) / d t$, although included, is quite small compared with the sink term putting the concentration of ozone in a pseudo-steady state. 


\section{Steady states}

A steady-state assumption, when it can be made, is highly desirable because it converts the differential mass balance equations (7) into algebraic expressions that are easy to apply and clearly show the functional dependencies of the concentration on the sources, sinks and precursors. Steady states arise when there are sustained sources and sinks. There do not appear to be universally accepted definitions of the types of steady states that can occur, which contributes to misinterpretations of the consequences. In this paper we adopt the following definitions: in a normal steady-state (SS), the concentrations are constant in time over some suitably long period spanning many measurements, often reflecting sustained constancy of sources and sinks. In a pseudo-steady state, the concentrations are not constant between measurements, but adjust rapidly to changes in sources and sinks at time scales much shorter than the time between measurements. This makes $\mathrm{dC} / \mathrm{d} t$ much smaller than the other terms in the mass balance (Eqs. 5 or 6 ) and relative to the sinks in particular. If $\mathrm{d} C / \mathrm{d} t$ is calculated as $\delta C / \delta t$ where $\delta t$ is the time between measurements, then a pseudo-steady state occurs (PSSA) if $\tau$ « $\delta t$, where $\tau$ is the composite lifetime $=\left[1 / \tau_{\text {Chemical }}+1 / \tau_{\text {Transport }}+1 / \tau_{\text {Other }}\right]^{-1}$. For the pseudo-steady state to occur it doesn't matter whether the $\tau$ is a chemical lifetime, transport time or a combination of the two. In this way, transport processes can push the system into a pseudo-steady state for ozone even when the chemical processes are out of balance. In a pseudo-steady state the concentration $\mathrm{C}\left(=\mathrm{NO}, \mathrm{NO}_{2}\right.$, or $\left.\mathrm{O}_{3}\right)$ is:

$C=\left(P+T_{\mathrm{IN}}\right) /\left(1 / \tau_{\text {Chem }}+1 / \tau_{\mathrm{T}}\right)$

A photo-stationary state (PSS) can occur during daytime when the net chemical production is zero; that is, the sources and sinks, at least one of which is photo-chemically driven, are in equilibrium with each other. ${ }^{19,20} \mathrm{~A}$ photo-stationary state cannot occur if there are terms in addition to net chemical production in the mass balance because $\mathrm{d} C / \mathrm{d} t=0$ will, in general, require that $P_{\mathrm{Net}} C=-T_{\mathrm{Net}} \mathrm{C}+\mathrm{C} / \tau_{\text {other }} \neq 0$

A hypothetical photo-stationary state (HPPS), defined in this work, is a calculation of the concentration a gas would have in a steady state with its chemical sources and sinks. HPSS is not expected to occur in actual circumstances except in a temporary transitional state. We will use this concept to apportion the ozone concentration at our sites between local chemical production and transport.

\section{Validity of steady states}

We can catagorize all possibilities to determine when pseudo-steady states and photo-stationary states can occur for the ozone chemical cycles. Key variables that affect steady states are: Ozone transport, VOCs through peroxy radicals and local sources $\left(S_{\mathrm{NO}_{1}} S_{\mathrm{NO}_{2}}\right)$ most likely represented by transport as $T_{\mathrm{Net}} \mathrm{NO}$ and $T_{\mathrm{Net}} \mathrm{NO}_{2}$. We look at three cases that cover all possibilities: (1) No VOCs and no transport; (2) VOCs added but no transport; (3) transport added whether VOCs are present or not.

In the first case, Eqs. (1-3) and (7) show that $\mathrm{O}_{3}, \mathrm{NO}$, and $\mathrm{NO}_{2}$ will come into a pseudo-steady state provided the lifetimes are short enough as during daytime. Then, $P_{\mathrm{Net}} \mathrm{O}_{3}=P_{\mathrm{Net}} \mathrm{NO}=P_{\mathrm{Net}} \mathrm{NO}_{2}=0$. This is the frequently cited text-book situation of a photo-stationary state for $\mathrm{O}_{3}, \mathrm{NO}$ and $\mathrm{NO}_{2}$. It leads to the relationship: $\left(\mathrm{O}_{3}\right)_{\mathrm{PSS}}=J_{\mathrm{NO} 2}\left(\mathrm{NO}_{2}\right) / \mathrm{K}_{4}(\mathrm{NO})$ (see ref. ${ }^{20}$ for example). The conditions under which this can occur may exist in a reaction chamber, but not in any real urban environment.

Once the VOCs are added, our second case, peroxy radicals are produced during daytime and with no transport, Eqs. (1-3) and (7) show that a photo-stationary state of $\mathrm{NO}$ and $\mathrm{NO}_{2}$ can occur if the lifetimes are short enough but for ozone there can be neither a photo-stationary state nor a pseudo-steady state because:

$\mathrm{d}\left(\mathrm{O}_{3}\right) / \mathrm{d} t=P_{\mathrm{Net}} \mathrm{O}_{3}=k_{2}\left(\mathrm{R} \mathrm{O}_{2}\right)(\mathrm{NO})>0$

It should be noted that this condition requires increasing concentrations of ozone while the normal daily ozone cycle has a decreasing period after the peak which would be inexplicable with this assumption. If either NO or $\mathrm{NO}_{2}$ is in a photo-stationary state, the other will be also based on the core chemical theory. This case is included for completeness and, like the previous one, cannot occur in any real urban or regional polluted environment. This is because the transport of $\mathrm{NO}$ and $\mathrm{NO}_{2}$ to the observation site always occurs and cannot be neglected in the mass balance as we discuss next.

Even though the local lifetimes of $\mathrm{NO}$ and $\mathrm{NO}_{2}$ are short, they are nonetheless transported to the site of the observations from more distant sources because of the constant re-generation due to reactions R3 and R4 that make NOx a nearly conserved quantity subject only to dilution during transport and losses by the slower cycle-terminating reactions. Looking at it another way, the $\mathrm{NO}$ and $\mathrm{NO}_{2}$ at the observation site cannot both be generated locally because their origins are in high temperature combustion in engines. At least one of them must be continually brought to the site from the sources if both are being observed.

The situation for $\mathrm{NO}$ and $\mathrm{NO}_{2}$ is different from other reactive chemical species such as the peroxy radicals, because of the constant regeneration between the two as they travel from the source to the point of observation. For the peroxy radicals, all production and destruction is local, and the transported air brings only the VOC precursors and not the peroxy radicals themselves, which, once lost, have to be produced from a fresh supply of the precursors and not the products of the loss process. Hence the occurrence of a pseudo-steady state also generates a photostationary state for the peroxy radicals because of smallness of the net transport term. This is also the case for other fast reacting radicals in the ozone cycle, such as $\mathrm{O}$ or $\mathrm{OH}$. In a general sense, the phenomenon that leads to $\mathrm{NO}$ and $\mathrm{NO}_{2}$ transport is present when there are interactions between two or more gases, as in catalytic cycles, that make the lifetime of a gas appear short due to the reaction internal to the cycle, but acts as if it was long due to the slowness of the cycle-terminating chemical reactions. So, for point of observation $P_{\mathrm{Net}} \mathrm{C}$ calculations of $\mathrm{NO}, \mathrm{NO}_{2}$, and $\mathrm{O}_{3}$, it is the local lifetimes that apply, but for the transport of these gases from sources to the sites of observation the longer lifetimes, due to termination reactions and dilution are applicable. For ozone too, the local lifetime may be short, but as the air mass moves away from the site, ozone is regenerated within this air mass and would thus persist over long distances as it is slowly lost due to cycle-terminating sinks such as deposition, and dilution driven by turbulent transport processes.

In the remaining case, when transport is added, whether there are VOCs present or not, it is apparent from the discussion above that ozone cannot be in a photo-stationary state (Eq. 7), however it will most likely achieve a pseudo-steady state (that is, $\mathrm{d} C / \mathrm{d} t=0$ and $P_{\mathrm{Net}} C=-T_{\mathrm{Net}} C+C / \tau_{\text {other }} \neq 0$ ). Comparing it to the first case, the presence of VOCs alone takes ozone out of both the photo-stationary state and the pseudo-steady state. Adding transport restores the pseudo-steady state but not the photo-stationary state. Equations (1-3) and (7) show that, $\mathrm{NO}$ and $\mathrm{NO}_{2}$ cannot be in a photostationary state once transport is included, although they can achieve a pseudo-steady state due to their short local lifetimes. In this case, $P_{\mathrm{Net}} \mathrm{NO}$ $=-T_{\mathrm{Net}} \mathrm{NO}$ and $P_{\mathrm{Net}} \mathrm{NO}_{2}=-T_{\mathrm{Net}} \mathrm{NO}_{2}$ and hence are not zero as would be required by a photo-stationary state assumption. The Yanbu data verify that major transport of ozone, $\mathrm{NO}$ and $\mathrm{NO}_{2}$ is required to explain the observations as shown in the Figs. 2-4.

The idea is frequently promoted that because of the short lifetimes of $\mathrm{NO}, \mathrm{NO}_{2}$, and $\mathrm{O}_{3}$ they come into steady state very quickly. This is indeed the case, but we see that it is a pseudo-steady state (PSSA) and it does not mean that the net chemical production is in steady state (PSS), that is, $P_{\mathrm{Net}} \mathrm{C}=0$ as is then assumed. The assumption that $P_{\mathrm{Net}} C=0$ is the contrary to the conservation law embodied in the fundamental mass balance Eq. (5) and the preceding discussion about the ever-present transport of all three gases.

Whether there is a pseudo-state or not can be easily tested by comparing measured $\mathrm{d} C / \mathrm{d} t$ to the other terms in the mass balance. For our case we adopt the criterion: $\mathrm{d} C / \mathrm{d} t=0$ if $|\mathrm{d} C / \mathrm{d} t| \leq 10 \%$ of any of the other terms, namely production, loss, $T_{\mathrm{IN}}$ or $T_{\mathrm{OUT}}$ in the mass balance. Applying this criterion, using the sink term for $\mathrm{O}_{3}$ and $\mathrm{NO}$ and the production term for $\mathrm{NO}_{2}$, we find that at Yanbu, the $\mathrm{dC} / \mathrm{d} t$ term is $<10 \%$ of the other terms for $\mathrm{O}_{3}$ and $\mathrm{NO}_{2}$ and $<5 \%$ for NO. This establishes that all three gases are in a pseudo-steady state.

Having established the lack of photo-stationary states for $\mathrm{NO}$ and $\mathrm{NO}_{2}$, we can look at the nexus with the literature where these assumptions were commonly made. From Eqs. (1-4) we see that:

$P_{\mathrm{Net}} \mathrm{O}_{3}=k_{2}\left(\mathrm{R} / \mathrm{O}_{2}\right)(\mathrm{NO})+P_{\mathrm{Net}} \mathrm{NO}$

$P_{\mathrm{Net}} \mathrm{O}_{3}=\sum_{i} k_{i}(\mathrm{VOC}) i(\mathrm{OH})+P_{\mathrm{Net}} \mathrm{NO}$

In many past publications Eqs. (12) and (13) are used with the invalid assumption that $P_{\mathrm{Net}} \mathrm{NO}=0$, that is, a photo-stationary state is assumed for $\mathrm{NO}$ and $\mathrm{NO}_{2}$. Net ozone production is calculated as: $P_{\mathrm{Net}} \mathrm{O}_{3}=\sum_{i} k_{i}(\mathrm{VOC}) i$ $(\mathrm{OH})$ from Eq. (13). It is then used to rank the importance of specific VOCs in the production of ozone (see ref. ${ }^{5}$ for example). This is desirable when peroxy radicals or $J_{\mathrm{NO} 2}$ are not measured. Eqn (12) with the assumption of photo-stationary state of $\mathrm{NO}$ is often used to calculate the concentrations of peroxy radicals by inversion and using the right hand side of Eq. (1) for $P_{\mathrm{Net}} \mathrm{O}_{3}$, that is, $\left(\mathrm{R}^{\prime} \mathrm{O}_{2}\right)=\left[J_{\mathrm{NO} 2}\left(\mathrm{NO}_{2}\right)-k_{4}\left(\mathrm{O}_{3}\right)\right] / k_{2}(\mathrm{NO}) .{ }^{21-25}$ It adds 
information when peroxy radicals are not measurable by the available instrumentation, as is often the case. In both cases the assumption of a photo-stationary state of NO leads to inaccurate underestimates of the net ozone production. When direct measurements of peroxy radicals are available these indirect calculations do not match observations. ${ }^{21}$ The disagreement is presumed to be caused by missing chemistry, however, it is due to the faulty assumption that $\mathrm{NO}$ and $\mathrm{NO}_{2}$ are in a photo-stationary state and hence transport is neglected, when in fact it can act as an apparent source or $\operatorname{sink}^{5,21-25}$ For instance, a re-interpretation of the published data from Pabstthum, Germany ${ }^{21}$ show maximum net ozone production rates calculated from Eq. (1) were $80-120 \mathrm{ppb} / \mathrm{h}$ on some days, similar to the Yanbu observations reported here. Since peroxy radical measurements were taken in this experiment, results show that the $k_{2}\left(\mathrm{R}^{\prime}\right.$ $\mathrm{O}_{2}$ ) (NO) term in Eq. (12) is only $\sim 15 \mathrm{ppb} / \mathrm{h}$ or $\sim 20 \%$ of $P_{\mathrm{Net}} \mathrm{O}_{3}$ from Eq. (1) for the same days. The rest $\sim 60-70 \mathrm{ppb} / \mathrm{h}$ is from the $P_{\mathrm{Net}} \mathrm{NO}$ term in Eq. (12). The NO transport therefore, can balance the net ozone production without requiring unknown atmospheric chemistry.

The Leighton ratio reinterpreted

The classically defined Leighton ratio is $\mathrm{ProdO}_{3} / \mathrm{LossO}_{3}$ or:

$\Phi=J_{\mathrm{NO} 2}\left(\mathrm{NO}_{2}\right) / k_{4}(\mathrm{NO})\left(\mathrm{O}_{3}\right)$

As such it contains the same information as the net ozone production $P_{\mathrm{Net}} \mathrm{O}_{3}$ in the core chemistry R1-R4. It is unity if the circumstances satisfy the photo-stationary state for all three gases $\left(\mathrm{NO}, \mathrm{NO}_{2}\right.$, and $\left.\mathrm{O}_{3}\right)$ and its departures from unity are sometimes used as a test of the role of VOCs in a situation of interest and it is frequently assumed to be determined only by chemical processes. This assumption however, can be valid only if there is no net transport of ozone and its precursors.

The Leighton ratio can be interpreted to separate the role of chemistry and transport. We can ask: What would be the concentration of $\mathrm{O}_{3}$ if it was in a hypothetical photo-stationary state (HPSS) with the actual or measured $\mathrm{NO}, \mathrm{NO}_{2}$ and $J_{\mathrm{NO} 2}$ ? We can calculate this from measurements as:

$\left(\mathrm{O}_{3}\right)_{\text {HPSS }}=J_{\text {NO2-Actual }}\left(\mathrm{NO}_{2}\right)_{\text {Actual }} / k_{4}(\mathrm{NO})_{\text {Actual }} \neq\left(\mathrm{O}_{3}\right)_{\text {Actual }}$

$\left(\mathrm{O}_{3}\right)_{\text {Actual }}$ or just $\left(\mathrm{O}_{3}\right)$ is the actual, measured ozone concentration $\left(\mathrm{O}_{3}\right)$ and it can be written as:

$\left(\mathrm{O}_{3}\right)=\left(\mathrm{O}_{3}\right)_{\mathrm{HPSS}}+\delta\left(\mathrm{O}_{3}\right)$,

where $\delta\left(\mathrm{O}_{3}\right)$ is the departure of the actual ozone concentration from HPSS.

By combining (1), (7) and (16) with the assumption that $\mathrm{O}_{3}$ is in a pseudo-steady state we see that:

$\delta\left(\mathrm{O}_{3}\right)=T_{\mathrm{Net}} \mathrm{O}_{3} \tau \mathrm{O}_{3}$,

where $\mathrm{TO}_{3}$ is the lifetime of ozone due to its reaction with $\mathrm{NO}$, that is, $\mathrm{TO}_{3}=1 /\left[k_{4}(\mathrm{NO})\right]$. We see that the departure from the HPSS is represented by the net transport of ozone and its lifetime when ozone mass balance satisfies the pseudo-steady state assumption. The role of VOCs is to increase the lifetime of ozone by shifting $\mathrm{NO}$ to $\mathrm{NO}_{2}$ and is therefore represented by $\mathrm{TO}_{3}$ in Eq. (17). In this manner, the existence of a pseudosteady state does not result in a photo-stationary state.

The $\delta\left(\mathrm{O}_{3}\right)$ is closely related to the Leighton ratio $(\Phi)$ as:

$\Phi=1-\delta\left(\mathrm{O}_{3}\right) /\left(\mathrm{O}_{3}\right)$

or:

$\Phi=\left(\mathrm{O}_{3}\right)_{\text {HPSS }} /\left(\mathrm{O}_{3}\right)$

Using Eq. (18) we may interpret the term $\delta\left(\mathrm{O}_{3}\right) /\left(\mathrm{O}_{3}\right)$ as the fraction of ozone that comes from import or export of ozone at the site. Then $\Phi$ is the fraction of the locally produced ozone that stays at the site. The upper limit of the term $\delta\left(\mathrm{O}_{3}\right) /\left(\mathrm{O}_{3}\right)=1$ when $\left(\mathrm{O}_{3}\right)_{\mathrm{HPSS}}=0$ and $\Phi=0$ as at night. Then all the ozone at the site is imported. If $\delta\left(\mathrm{O}_{3}\right) /\left(\mathrm{O}_{3}\right)=0, \Phi=1$ means that all the ozone produced stays at the site and nothing is imported or exported in the net. The $\delta\left(\mathrm{O}_{3}\right) /\left(\mathrm{O}_{3}\right)$ term can, however, be any negative number if ozone is rapidly moved out making it less than $\left(\mathrm{O}_{3}\right)_{\text {HPSS }}$ and thus making $\Phi$ $>1$. These ideas are applied to the Yanbu data showing the Leighton ratio in Fig. 5 and the related variable $\delta\left(\mathrm{O}_{3}\right)$ which describes when and what amount of the ozone at the site is imported or exported.

This method offers further insights in the frequently assumed situation that peroxy radicals are present but there is no transport. Then $\delta\left(\mathrm{O}_{3}\right)=$ $T_{\mathrm{Net}} \mathrm{O}_{3} \mathrm{TO}_{3}$ is an indeterminate quantity $(0 / 0)$ under the pseudo-steady state assumption required to derive this relationship. Therefore, $\Phi$ cannot be calculated using Eq. (18). Assuming that $\mathrm{NO}$ and $\mathrm{NO}_{2}$ are in a photo-
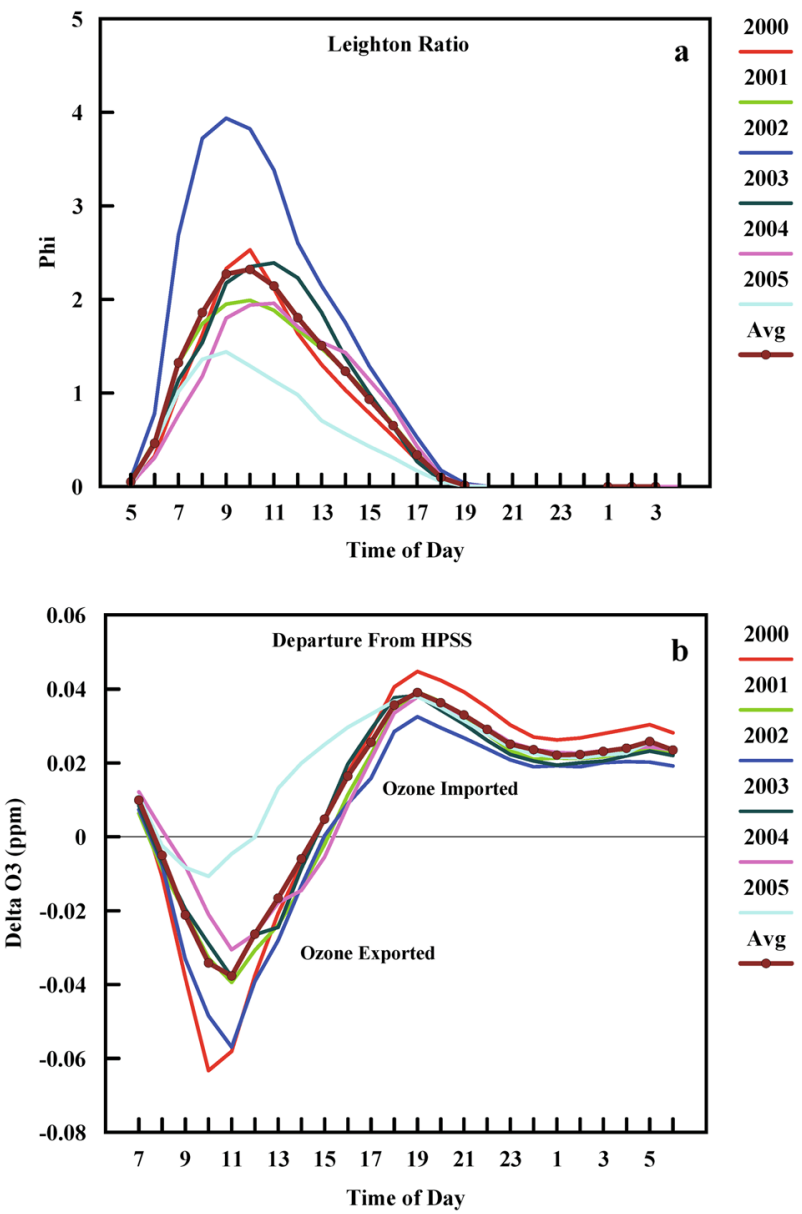

Fig. 5 a The Leighton ratio, $\mathbf{b} \delta\left(\mathrm{O}_{3}\right)$ representing the departure of the observed ozone from a hypothetical photo-stationary state. The departure of the Leighton ratio from 1 is driven by the presence of peroxy radicals generated from the oxidation of the VOCs and by transport process that carry ozone and its pre-cursors to and from the location of the measurements

stationary state, which can exist if transport is neglected, even though ozone cannot be in such a state (our earlier Case 2), and using the defining equation for $\Phi$ we see that:

$\Phi=1+\tau \mathrm{NO}_{\mathrm{O} 3} / \tau \mathrm{NO}_{\mathrm{R} / \mathrm{O} 2} \geq 1$,

where $\mathrm{TNO}_{\mathrm{O} 3}$ and $\mathrm{TNO}_{\mathrm{R}^{\prime} \mathrm{O} 2}$ are the chemical lifetimes of $\mathrm{NO}$ with respect to reactions with ozone and peroxy radicals, that is, $1 / k_{4}\left(O_{3}\right)$ and $1 / k\left(R^{\prime} O_{2}\right)$. The effect of adding peroxy radicals is to increase the Leighton ratio above unity. In this case, there is no way for the ratio to be less than 1 , yet it is often observed to be so, as in Fig. (5a) and elsewhere. ${ }^{26-29}$ The values of the ratio less than one can only be caused by transport processes.

Data availability

The data used in this study are available as a Microsoft Excel file in the Supplementary Material.

\section{ACKNOWLEDGEMENTS}

Support for this project came from Andarz Co and its resources. Additional support came from the Center for Climate and Aerosol Research and the Institute of Sustainable Solutions at Portland State University. I thank Drs. C. Butenhoff and R.M. Harrison for their many contributions to this research project. This project came from a followup of a collaborative agreement with King Abdulaziz University under grant no. (4-10-1432/HiCi). The Presidency of Meteorology and Environment (PME) in Saudi Arabia provided the observational data sets as released in previous publications with their collaboration. 


\section{ADDITIONAL INFORMATION}

Supplementary information accompanies the paper on the npj Climate and Atmospheric Science website (https://doi.org/10.1038/s41612-018-0035-7).

Competing interests: The authors declare no competing interests.

Publisher's note Springer Nature remains neutral with regard to jurisdictional claims in published maps and institutional affiliations.

\section{REFERENCES}

1. WHO. Ambient (outdoor) Air Quality and Health. http://www.who.int/ mediacentre/factsheets/fs313/en/ (2015).

2. WHO. Air Quality Guidelines for Particulate Matter, Ozone, Nitrogen Dioxide and Sulfur Dioxide: Summary of Risk Assessment. (WHO, Geneva, 2006).

3. United States Environmental Protection Agency, Air Quality Index: a guide to your health (EPA-456/F-14-002) (2015).

4. National Academy of Sciences. Rethinking the Ozone Problem in Urban and Regional Air Pollution. (NRC, Washington DC, 1991).

5. Kleinman, L. I. et al. Ozone production rate and hydrocarbon reactivity in 5 urban areas: a cause of high ozone concentration in Houston. Geophys. Res. Lett. 29, 1467 (2002).

6. Thornton, J. A. et al. Ozone production rates as a function of NOx abundances and $\mathrm{HOx}$ production rates in the Nashville urban plume. J. Geophys. Res. 107, 4146 (2002).

7. Sillman, S. \& He, D. Some theoretical results concerning $\mathrm{O}_{3}-\mathrm{NOx}-\mathrm{VOC}$ chemistry and NOx-VOC indicators. J. Geophys. Res. 107, 4659 (2002).

8. Khalil, M. A. K. et al. Air quality at Yanbu, Saudi Arabia. J. Air Waste Manage. Assoc 66, 341-355 (2015)

9. WeatherSpark. Beautiful Weather Graphs and Maps. https://weatherspark.com/ (2015) The data are no longer being supplied: https://www.facebook.com/ WeatherSpark-270402379655175/.

10. Khalil, M. A. K., Butenhoff, C. L., Harrison, R. M. Ozone balances in urban Saudi Arabia, (In Press, 2018)

11. Viviano, F. Kingdon on the edge: Saudi Arabia, National Geographic Magazine, http://ngm.nationalgeographic.com/features/world/asia/saudi-arabia/saudiarabia-text/ (2003).

12. Hassan, I. A., Basahi, J. M., Ismail, I. M. \& Habeebullah, T. M. Spatial distribution and temporal variation in ambient ozone and its associated NOx in the atmosphere of Jeddah City, Saudi Arabia. Aerosol Air Qual. 13, 1712-1722 (2013). ISSN: 16808584 print / 2071-1409.

13. Butenhoff, C. L. et al. Evaluation of ozone, nitrogen dioxide and carbon monoxide at nine sites in Saudi Arabia during 2007. J. Air Waste Manage. Assoc 65, 871-886 (2015).

14. Porter, W. C. et al. Annual and weekly patterns of ozone and particulate matter in Jeddah, Saudi Arabia. J. Air Waste Assoc. 64, 817-826 (2014).

15. VanCuren, R. Transport aloft drives peak ozone in the Mojave Desert. Atmos. Environ. 109, 331-341 (2015).

16. Khalil, M. A. K. \& Rasmussen, R. A. Modeling chemical transport and mass balances in the atmosphere. Chapter 2. In: W. B. Neely, G. E. Blau Editors. Environmental Exposure from Chemicals (pp. 21-54. CRC Press, Boca Raton, Florida, 1984). Vol. II.
17. Platt, U., LeBras, G., Poulet, G., Burrows, J. P. \& Moortgat, G. Peroxy radicals from night-time reaction of $\mathrm{NO}_{2}$ with organic compounds. Nature 348, 147-149 (1990).

18. Mentel, Th. F., Bleilebens, D. \& Wahner, A. A study of nighttime nitrogen oxide oxidation in a large reaction chamber - the fate of $\mathrm{NO}_{2}, \mathrm{~N} 2 \mathrm{O} 5$, and $\mathrm{O}_{3}$ at different humidities. Atmos. Environ. 30, 4007-4020 (1996).

19. IUPAC. Photostationary State, https://goldbook.iupac.org/P04654.html (2017).

20. Seinfeld, J. H. \& Pandis, S. N. Atmospheric Chemistry and Physics. (Wiley, New York, 1998).

21. Andreas Volz-Thomas et al. Inorganic trace gases and peroxy radicals during BERLIOZ at Pabstthum: an investigation of the photostationary state of NOx and $\mathrm{O}_{3}$. J. Geophys. Res. 108, 8248 (2003).

22. Mannschreck, K., Gilge, S., Plass-Duelmer, C., Fricke, W. \& Berresheim, H. Assessment of the applicability of $\mathrm{NO}-\mathrm{NO}_{2}-\mathrm{O}_{3}$ photostationary state to long-term measurements at the Hohenpeissenberg GAWStation, Germany. Atmos. Chem. Phys. 4, 1265-1277, www.atmos-chem-phys.org/acp/4/1265/ (2004). SRef-ID: 1680-7324/acp/2004-4-1265.

23. Griffin, R. J., Beckman, P. J., Talbot, R. W., Sive, B. C. \& Varner, R. K. Deviations from ozone photostationary state during the International Consortium for Atmospheric Research on Transport and Transformation 2004 campaign: Use of measurements and photochemical modeling to assess potential causes. J. Geophys. Res. 112, D10S07 (2007).

24. Cantrell, C. A. et al. Peroxy radicals from photostationary state deviations and steady state calculations during the tropospheric $\mathrm{OH}$ photochemistry experiment at Idaho Hill, Colorado. J. Geophys. Res. 102, 6369-6378 (1997).

25. Cantrell, C. A. et al. Steady state free radical budgets and ozone photochemistry during TOPSE. J. Geophys. Res. 108, 8361 (2003).

26. Shetter, R. E., Stedman, D. H. \& West, D. H. The $\mathrm{NO} / \mathrm{NO}_{2} / \mathrm{O}_{3}$ photostationary state in Claremont, California. J. Air Pollut. Control Assoc. 33, 212-214 (1983).

27. Bruning, F. R. et al. Mixing ratios and photostationary state of $\mathrm{NO}$ and $\mathrm{NO}_{2}$ observed during the POPCORN field campaign at a rural site in Germany. J. Atmos. Chem. 31, 119-137 (1998).

28. Chate, D. M. et al. Deviations from the O3eNOeNO2 photo-stationary state in Delhi, India. Atmos. Environ. 96, 353-358 (2014).

29. Matsumoto, J. et al. Examination on photostationary state of NOx in the urban atmosphere in Japan. Atmos. Environ. 40, 3230-3239 (2006).

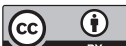

Open Access This article is licensed under a Creative Commons Attribution 4.0 International License, which permits use, sharing, adaptation, distribution and reproduction in any medium or format, as long as you give appropriate credit to the original author(s) and the source, provide a link to the Creative Commons license, and indicate if changes were made. The images or other third party material in this article are included in the article's Creative Commons license, unless indicated otherwise in a credit line to the material. If material is not included in the article's Creative Commons license and your intended use is not permitted by statutory regulation or exceeds the permitted use, you will need to obtain permission directly from the copyright holder. To view a copy of this license, visit http://creativecommons. org/licenses/by/4.0/.

(c) The Author(s) 2018 